\title{
Q\&A
}

\section{Reporting Noncompliance in the Animal Facility}

As a technician, what can I do if I see evidence of noncompliance on the part of an investigator, another technician, or a veterinarian?

This is a question that animal caretakers should ask themselves every day. After all, they are the first line of defense in maintaining protection and humane care for animals.

The first step to combating noncompliance, including potential animal mistreatment, is to become familiar with the protocols that are underway in your facility. In these protocols, the Principal Investigator (PI) will have described exactly what is to be done with the animals, as well as possible signs and symptoms that the animals may display as a result of the experimental procedures. If your facility has a Compliance Officer or a Training Coordinator, he or she may be able to help you obtain the protocols so that you can read and ask questions about them. If not, your supervisor or the facility director should be able to locate the protocols that are of interest for you.

Most of the time, the animal caretakers or technicians will notice problems in the animals before the PI or the Clinical Veterinarian. If you find a situation in which you believe that the animals that you care for are not being treated appropriately, you have not only the right but also the responsibility to report such instances to your facility's IACUC Chairperson. You can do so anonymously, although in small facilities anonymity may not be possible. There should be a chain of command in place that the caretaker can go through to report the incident so that the quickest and most appropriate action can be taken. Then you can set out to write the IACUC about your allegation.

The IACUC Handbook ${ }^{1}$ is an excellent resource for anyone grappling with the idea of becoming a 'whistleblower', because it thoroughly describes the definitions and regulations pertaining to protocol noncompliance and animal mistreatment. If you decide to proceed in becoming a whistleblower, you should know that you (as an animal care technician or any other facility employee) are protected by the regulations issued under the Animal Welfare Act, which state, "No facility employee, Committee member, or laboratory personnel shall be discriminated against or be subject to any reprisal for reporting violations of any regulation or standards under the Act ${ }^{2}$." Unfortunately, this does not mean that people won't harbor resentments toward you because of the allegations and subsequent investigation by the IACUC. If you are willing to take some steps to get the correct information to your IACUC Chairperson, even if it's not anonymous, you will be providing a great service to your animals.

If you decide to go ahead with your complaint, the following steps are good ones to take:

- Document the situation including date(s), protocol number, investigator's name, species, number of animals involved, other distinctive information relating to the investigator's office number or lab room number, etc.

- Be specific. Do not include other situations that may have occurred with the same investigator.

- Describe the situation in terms that are as neutral as possible.

- State the relevant facts clearly and concisely.

- Leave out emotional overtones and personal opinions.

- Elicit the help of someone you trust who may be a good diplomatic letter writer or someone who can review your letter and offer editing suggestions before you send it.

If you have difficulty providing this information to your IACUC, then perhaps you can speak confidentially with an administrator at your company. If your efforts to deal with the situation internally do not produce results, other options include the following:

- Call a friend or colleague at another facility who can be supportive and helpful.

- Send an email to the TechLink, or another email list that serves laboratory animal care and use community. When sending an email, refer to your situation in general terms or 'what if' scenarios.

- Ask your facility director to provide formal training, prepare handouts and posters, or SOPs or other acceptable methods of information about the rights of individuals to bring complaints to the IACUC about animal care and use issues.

- Call an Animal Welfare Hotline.

During the investigation, ask the IACUC Chairperson about any progress in relation to the situation. When the time comes for the IACUC to give a response to your allegation, be prepared for the answer not to be exactly what you expect to hear. Even if the committee does not come to the decision you had hoped for, you can certainly ask for an explanation of the conclusions that were reached.

\footnotetext{
References

1. Silverman, J., Suckow, M.A. \& Murthy, S. The IACUC Handbook Ch. 29 (CRC Press, Boca Raton, FL, 2000).

2. $9 \mathrm{CFR} \S 2.32 \mathrm{c}, 4$
}

Vicki Koch, BS, RLATG

LAB ANIMAL welcomes reader questions. Please send your questions to: labanimal@natureny.com. 